\title{
Cultura política y economía moral en la rebelión de Huánuco, Panataguas y Huamalíes (1812)
}

\section{Political culture and moral economy in the Huánuco, Panataguas and Huamalíes rebellion (1812)}

\section{Eduardo Torres Arancivia}

Pontificia Universidad Católica del Perú*

\section{Resumen}

Luego de doscientos años del levantamiento en los partidos de Huánuco, aun son recurrentes las versiones historiográficas que engloban a esa rebelión en un supuesto ciclo de movimientos emancipadores o preindependentistas. Frente a esas voces, este artículo analiza la cultura política de los alzados para descubrir que en esa cultura aún perduraban elementos de los siglos XVI y XVII, que tienen que ver con el intento de reflotar el pacto social con la monarquía. En ese sentido, y aplicando el modelo de E.P Thompson, estas páginas buscan sustentar que el movimiento de 1812 era una expresión de economía moral, es decir, que frente a un intento modernizador del Estado, algunos estamentos de la sociedad buscan defender costumbres y derechos tradicionales que suelen basarse en argumentos paternalistas, religiosos y morales.

* Doctor en Estudios Andinos por dicha universidad.

Contacto: torres.el@pucp.edu.pe 
Palabras claves: Perú, rebeliones, siglo XIX, Huánuco, cultura política

\section{Abstract}

After two hundred years of the uprising in Huánuco territories there are still recurrent historiographical versions that include the rebellion in an alleged cycle of pre-emancipatory movements. Faced with these opinions, this article analyzes the political culture of those rebels to verify that in their culture still remained beliefs and attitudes of the sixteenth and seventeenth centuries, which explain their attempt to update the social pact with the monarchy. In that sense, applying the model of E.P. Thompson, this work proposes that the movement of 1812 was an expression of moral economy, that is, when a state attempts a modernizing change, some sectors of the society seek to defend traditional customs and rights often based on paternalistic, religious and moral grounds.

Keywords: Peru, rebellions, XIX century, Huánuco, political culture 


\section{Introducción}

\section{Un estado de la cuestión}

"La alteración de los partidos de Huánuco de que hablaré después [...]". Con esta frase el virrey José de Abascal anunciaba en su Memoria de Gobierno el tratamiento que le iba a dar a una rebelión que, en 1812, y por algo más de un mes, sacudió la ceja de selva del virreinato peruano (Abascal 1944 [1816]: vol. II: 380). Lamentablemente, el gobernante del Perú - tal vez movido por preocupaciones mucho más trascendentes que remecían a América del Sur- obvió narrar los hechos prometidos y, lo que es más importante, emitir su juicio o apreciación sobre tales sucesos. En cierta forma, la omisión era comprensible: el nuevo escenario político que las Cortes de Cádiz habían auspiciado, la defensa militar del reino, la rebelión del Cuzco de 1814 y la pobreza económica del Perú debieron haber captado casi toda la atención del diligente y disciplinado vicesoberano.

Lo curioso es que algo parecido a la omisión virreinal ha pasado con respecto a la historiografía nacional, que no ha sido muy dada al análisis interno de los movimientos rebeldes de inicios del siglo XIX. Arrojada al cajón de las antiguallas, la rebelión de Huánuco recién apareció como tema de interés en 1902 a raíz de unos artículos que, ofrecidos por entregas con el título de Historia Vieja, fueron publicados en el diario El Comercio de Lima por el "protohistoriador" cajamarquino Aníbal Gálvez (1865-1922). Luego, en 1912 y por el aniversario del centenario de la Constitución Gaditana y de varios movimientos insurrectos, Luis Antonio Eguiguren revivió el tema de la insurrección de Huánuco, Panataguas y Huamalíes en Guerra separatista del Perú. La rebelión de León de Huánuco. 1812, estudio dentro de una línea tradicional y positivista, más bien orientado a la glosa del documento inédito. 
El mismo título de la obra apunta a una tendencia que, con el devenir de los años, casi tomaría cariz de sentencia: los movimientos rebeldes de los primeros quince años del siglo XIX fueron ejemplos heroicos de propuestas políticas separatistas que venían germinándose desde fines del siglo XVIII.

Un loable esfuerzo de sistematización de los sucesos aquí referidos fue llevado a cabo por el escritor huanuqueño José Varallanos (1908-1997) en su monumental Historia de Huánuco de 1959 (que aquí se reseña con profusión). En esa obra analiza históricamente a la provincia desde los tiempos preincas hasta mediados del siglo XX y la rebelión de 1812 aparece contextualizada y muy bien ordenada. Los actores sociales y sus propuestas políticas son retratados por el autor de forma casi literario-narrativa. Debe resaltarse que Varallanos intentó sustentar sus propuestas con material de archivo valioso que en aquel entonces se mantenía inédito. Este autor propone un prenacionalismo que va en pos de la independencia de España. Además, contextualiza la rebelión huanuqueña como una revolución libertaria, ideológicamente más cercana a procesos como la independencia de los Estados Unidos o la Revolución francesa.

A fines de la década de 1960 apareció otra obra monumental: la Historia general del Perú del sacerdote Rubén Vargas Ugarte. Este historiador de metodología positivista también trató la rebelión de Huánuco y reconoció que de ella "no se ha dado una auténtica versión” (Vargas Ugarte 1966: 238). Este investigador buscaba —como hijo de su época- una versión fidedigna y verdadera de los hechos, pero veía que la documentación sobre los referidos sucesos era muy confusa y que no se delineaban las propuestas de los rebeldes más allá del enojo por las vejaciones de las que eran objeto, tanto los indígenas como mestizos y criollos de la zona, por parte de los europeos peninsulares. Salvo una buena condensación de los hechos, no se percibe un intento de parte de Vargas Ugarte 
por postular una propuesta sobre los hechos expuestos más allá de enmarcar a la rebelión en un "primer periodo de la revolución” en el largo camino de la emancipación.

El sesquicentenario de la independencia del Perú (1971) fue la oportunidad dorada para que se retomaran los estudios historiográficos sobre la materia. El acicate, sin lugar a dudas, fue la publicación de la Colección Documental de la Independencia ${ }^{1}$, ciclópeo esfuerzo de historiadores nacionales de aquel entonces que logaron publicar en casi un centenar de volúmenes la documentación más relevante sobre el proceso independentista peruano. No obstante, pronto comenzaron las críticas de varios sectores de izquierda que atacaron a la CDIP con argumentos ad hominen más que académicos. Quedó la sensación de que como los historiadores que llevaron a cabo el proyecto de la CDIP pertenecían a una generación que creía que la independencia del Perú había sido un largo proceso que partía desde el siglo XVIII y que tenía como eje la consolidación de una idea de nación peruana, la historiografía de corte marxista trataba de desvirtuar el esfuerzo. Lamentablemente, el estigma a tan importante conjunto documental se ha mantenido hasta nuestros días. Olvidada en estantes, los jóvenes investigadores rara vez se acercan al caudal de información que desfila en las páginas de la CDIP. Como ayer, aun se cree que los documentos ahí contenidos tienen un sesgo romántico. Nada más alejado de la realidad.

La gran ventaja de la CDIP es que al pretender sus editores encontrar las raíces de la independencia peruana, se remontaron hasta los tiempos de la gran rebelión de 1780 y así los volúmenes se multiplicaron para felicidad del investigador interesado. Como era de esperarse, varios tomos estuvieron dedicados a las rebeliones del siglo XIX y cinco volúmenes a

1 De aquí en adelante CDIP. 
la revolución de Huánuco, Panatahuas y Huamalíes de 1812 (Comisión Nacional del Sesquicentenario de la Independencia del Perú 1971: t. III, vols. 1, 2, 3, 4 y 5). Por primera vez se tenía reunida toda la documentación sobre este movimiento que fue presentada con un estudio preliminar de la historiadora Ella Dumbar Temple (1971).

No fue intención de Temple hacer un análisis historiográfico del movimiento de 1812 sino que, como ella misma subrayó, buscaba presentar el conjunto documental a todo interesado. En dicha presentación, la autora concluía que el estudio de la rebelión huanuqueña era aún un aspecto poco esclarecido a pesar de la envergadura del movimiento, que solo podía asemejarse a la gran rebelión de 1780. Las doce secciones de documentos, decía Temple, conformaban un corpus sistemático tan bien organizado que los temas a tratar en el futuro se multiplicarían. Así, tópicos como el retorno al incario, los conflictos entre criollos y peninsulares, la participación del clero en las revueltas, los aspectos económicos de una zona de frontera y el impacto de los repartos estaban a la espera de los historiadores.

Tal vez el primer análisis moderno y contextualizado del movimiento de Huánuco fue el de Heraclio Bonilla en un breve ensayo aparecido en La independencia en el Perú (Bonilla 1981). No obstante, más allá de narrar los hechos de forma ordenada y contextualizar el movimiento dentro de una esfera más amplia en concordancia con otras revueltas tampoco se intenta proponer un análisis amplio de la cuestión.

\section{Propósitos y tesis del presente estudio}

Ya que buena parte de los estudios que han abordado la rebelión de 1812 han obviado el análisis del contenido político 
del movimiento, este breve artículo intentará llenar ese vacío. En ese sentido, los objetivos planteados tienen que ver con qué tan cierta es la idea de que los criollos, mestizos e indios que participaron en las acciones rebeldes buscaban la ruptura con España. ¿Puede, pues, catalogarse como separatista a la rebelión de Huánuco, Panataguas y Huamalíes como lo han sostenido indirectamente algunos estudios? De antemano, se adelanta que la respuesta a esta pregunta inicial es no; el separatismo nunca fue una opción de los partícipes de la revuelta. Si no se buscaba la ruptura con respecto a España, ¿qué se pretendía entonces?

En este punto es cuando se debe hilar fino y se intentará un primer abordaje a la cultura política predominante en la zona de Huánuco a inicios del siglo XIX. Si no se buscaba la ruptura entonces, ¿cómo explicar la lógica del movimiento? La tesis que se plantea en este escrito es que la rebelión de Huánuco de 1812 fue una expresión de lo que la historiografía ha denominado economía moral. Más que buscar la ruptura con el sistema, los actores sociales que se rebelaron en la coyuntura de 1812 lo hicieron con el propósito de reactivar el pacto de antigua data que los unía con la monarquía ${ }^{2}$.

2 Dicho pacto pertenece a una compleja construcción del discurso político que asumía que el monarca católico debía alcanzar el buen gobierno. Dicho gobierno se materializaba cuando cada estamento de la sociedad corporativa recibía lo que le correspondía (en honores y preeminencias y no menos que en prelación) en virtud de su condición. Se entiende que esto último es el ejercicio de la justicia que Dios busca que se alcance entre los hombres constituidos en sociedad (Torres 2014: cap. 4, 5 y 7). El tratadista por excelencia que postuló la idea del pacto y que el poder, proveniente de Dios, va al pueblo que —organizado en sociedad — se lo delega al monarca para que gobierne con justicia fue Francisco Suárez en su De legibus. Más adelante se versará sobre él. Aquí, en el Perú, la obra de Guamán Poma de Ayala, si se ve como un tratado político, es un tremendo intento por recordar al monarca la idea de un pacto social 
Y la tesis se complica más puesto que los alzados de Huánuco no solo buscaban reactivar el pacto con su rey, a la sazón Fernando VII, sino que al intentarlo estaban retomando antiguas formas y creencias políticas que para el caso de la historia virreinal-colonial del Perú se podían rastrear en América hasta el siglo XVI y en la península ibérica hasta el Medioevo. En consecuencia, en los partidos de Huánuco se dio, en 1812, una lucha ideológica entre el Antiguo régimen y los intentos modernizantes de la corona borbónica que para aquél entonces afrontaba su más grave crisis política.

\section{E1 recuento de los hechos}

El mundo al revés, época de permisividad extrema, eso son los días de carnaval. Por un momento, los que están abajo tienen la oportunidad de ocupar el lugar de sus amos o superiores. Algo de eso ocurrió el 22 de febrero de 1812 cuando los indios de Panao, Pillao, Acomayo y Santa María del Valle llegaron a las puertas de la ciudad de Huánuco, armados todos ellos con hondas, palos y una que otra arma de fuego. Los defensores de la ciudad pronto salieron a darle el encuentro a la indiada y ambos grupos se enfrentaron en el puente Huayupampa, a pocos kilómetros de la ciudad. Muertos varios indios y el comandante de las fuerzas de defensa, la situación parecía estar controlada, pero a la mañana siguiente los indios volvieron a atacar. Según los testimonios recogidos, se señala que los indígenas no dejaban de repetir que iban solamente tras los europeos y no contra los criollos o mestizos.

entre los súbditos y el rey que debe garantizar el buen gobierno (Torres 2014: cap. 5). 
Con el propósito de apaciguar a los alzados, un grupo de vecinos y un par de sacerdotes salieron en comisión hacia ellos mientras los europeos peninsulares y algunas autoridades aprovecharon la negociación para abandonar la ciudad y ponerse a resguardo. Los indios, entonces, hicieron su ingreso a la ciudad pero la paz con la que entraron pronto se quebró para dar paso al saqueo de Huánuco, desmán que duró tres días en los que los vecinos y curas trataron de apaciguarlos; hasta se sacó en procesión la imagen de la Virgen de la Dolorosa para que los ánimos se calmaran.

Las autoridades españolas pronto recibieron los informes de los desventurados vecinos de Huánuco y ordenaron al intendente de Tarma, don José Gonzáles Prada que pacifique la región. Enteradas las poblaciones indígenas comarcanas que venía la fuerza pacificadora - por una serie de rumores y malentendidos — suponen que la represión será general y aniquiladora y los ánimos se caldearon a tal punto que unos dos mil indígenas salieron a hacerle frente a los españoles. El encuentro se produjo en Ambo el 5 de marzo con resultado desafortunado para las fuerzas de Gonzáles Prada. En otro escenario, en la ciudad de Huánuco, la situación fue bastante confusa. Se formó una junta gubernativa dirigida por Domingo Berrospi, Juan José Crespo y Castillo y Juan Antonio Navarro. Tal circunstancia fue vista con recelo; por un lado, la junta sustentó su nombramiento aduciendo que se debía lograr la pacificación de la zona con participación de los locales; por otro lado, las autoridades virreinales no tenían muy clara la participación de esta junta ni sabían cuán comprometida estaba con los hechos acontecidos.

Los indios, alentados por la victoria frente a los españoles, regresaron a Huánuco y exigieron que la junta tome partido. Berrospi dio a conocer su intención de sumarse a la protesta de los indios, pero en realidad estaba jugando una doble partida, pues mantenía nexos con las autoridades represoras 
para garantizar la lealtad al monarca. Descubierto en su juego, Berrospi fue destituido y reemplazado en el mando por Juan José Crespo y Castillo quien, dubitativamente por cierto, se vio acaudillando el movimiento.

Con refuerzos venidos de Cerro de Pasco, Gonzáles Prada regresó a Ambo y sostuvo la última batalla con los rebeldes el 17 de marzo. Como era de esperarse, las tropas del rey vencieron a los rebeldes. El día 20, el intendente de Tarma hizo su ingreso triunfal a Huánuco y pacificó la zona. Pronto comenzaron a caer los implicados más notorios de la rebelión, entre ellos Juan José Crespo y Castillo. Sometidos a proceso, muchos de los implicados fueron indultados, otros recibieron penas de trabajo forzado, exilio o prisión. Pocos fueron los que pagaron con la vida; entre ellos estaba Crespo y Castillo, que cayó abatido por un pelotón de fusilamiento el 8 de octubre de $1812^{3}$.

\section{Una zona siempre en ebullición}

Territorio de ceja de selva, la zona de Huánuco constituyó una zona de frontera. Como tal, su lógica de funcionamiento social y político era bastante peculiar con respecto a otras latitudes del virreinato peruano. Tarma y Pasco, territorios colindantes, compartían mucho de la misma lógica. Desde inicios del siglo XVIII, toda esta zona fue escenario de motines, revueltas y hasta rebeliones. Estas asonadas comenzaron muy temprano. En 1708 un corregidor sucumbía a manos de varios vecinos (O’Phelan 1988: 297); una revuelta estalló en el corregimiento de Huamalíes en 1732 por abu-

3 Sobre los hechos más notorios de la rebelión de Húanuco, véanse Comisión Nacional del Sesquicentenario de la Independencia del Perú (1971: t. III, vols. 1, 2, 3, 4 y 5); Varallanos (1959); Vargas Ugarte (1966); Bonilla (1981); Chassin (1989) y Puente (1993: 212). 
sos en los repartos de mercancías (Varallanos 1959: 436), mientras que en Tarma se detectaban movimientos de protesta contra los abusos de curas y doctrineros en 1719 y 1720 (O’Phelan 1988: 297). A su vez, la zona fue testigo de la rebelión más larga del siglo XVIII, la de Juan Santos Atahualpa (1742-1750). En todos estos movimientos, la constante era la protesta de los indígenas contra los malos funcionarios, los curas doctrineros y el abuso desmesurado de los corregidores. Entre 1764 y 1774, los abusos de estos funcionarios fue in crescendo, lo que desembocó en actos de extrema violencia en 1776 y 1777. En 1776, un corregidor de Huamalíes fue asesinado al mismo tiempo que su obraje era devorado por las llamas (O’Phelan 1988: 304), mientras que en 1777 los abusos del corregidor Ignacio de Santiago Ulloa colmó el ánimo de los indios, quienes se amotinaron (Varallanos 1959: 435-448).

Santiago Ulloa era casi el dueño del pueblo de Espíritu Santo de Llata; controlaba el tráfico de pepitas de oro, tenía obrajes, repartía mercancías y era el factótum de casi toda la ganadería del lugar. No obstante, tan grande como era su poder, también lo eran sus abusos hacia los indios, quienes cansados de la situación asesinaron a dos funcionarios cercanos al corregidor. Santiago Ulloa logró huir mientras que tropas enviadas ex profeso develaban la asonada rebelde; 13 personas fueron condenadas a muerte y 52 pasaron a prisión. La represión en esa zona era dura, pues había quedado muy traumatizada por los lances de Juan Santos, a tal punto que la militarización del lugar había sido la alternativa de la administración virreinal. A pesar del sofocamiento inicial, el malestar indígena no desapareció y el 28 de diciembre de 1777 los indios quemaron varias casas de europeos ${ }^{4}$. Los abusos

4 Se reseñan los sucesos ampliamente explicados en Varallanos (1959: 435-448). 
de Ignacio de Santiago Ulloa prosiguieron hasta 1780, año en el que criollos y hasta españoles, afectados esta vez por el mal obrar del funcionario, se alzaron en rebeldía.

El siglo XIX nos muestra otro escenario. La crisis de la monarquía española producto de la invasión napoleónica de 1808, más que generar sentimientos y acciones en pro de un separatismo con respecto a la península "exacerbó la confusión de propósitos en el Perú y polarizó las actitudes políticas" (Anna 2003: 87), que es lo que también ocurrió en Huánuco. La conformación de una junta central de gobierno que reinaría en nombre de Fernando VII en 1809, el reemplazo de este órgano por un consejo de regencia al año siguiente, el imperio de las Cortes de Cádiz entre 1810 y 1814, la sublevación de La Paz de 1809, la revolución de Buenos Aires de 1810, las incursiones de Castelli en el Alto Perú y su posterior derrota en Guaqui en 1812, sin duda, fueron resortes que activaron (o reactivaron) la cultura política en los partidos huanuqueños.

Hacia 1811, el abuso de los subdelegados (funcionarios que en la zona hacían las veces de los extintos corregidores) había colmado la paciencia de los habitantes de la zona de Huánuco. El poder estaba repartido de la siguiente manera:

Diego García era subdelegado del partido de Huánuco Alfonso de Mejorada era subdelegado del partido de Panataguas

Manuel del Real era subdelegado del partido de Huamalíes

Juan Bezares era subdelegado del partido de Chavín de Pariacca.

Y los abusos de estos individuos tenían que ver con acciones muy concretas que los indios, criollos y mestizos considera- 
ban un desvío del buen y recto gobierno. Se decía que tales funcionarios abusaban de sus cargos, usurpaban tierras, repartían los premios y oficios entre parientes y allegados, conformaban monopolios mercantiles, limitaban a su antojo el comercio de productos de pan llevar y propiciaban políticas especulativas (Varallanos 1959: 449-496).

En un plano general — que tiene que ver con la situación económica del virreinato peruano- la situación era de una alarmante pobreza por doquier. El Perú debía mantener económicamente la lucha armada contra los movimientos rebeldes que la política peninsular había auspiciado y tal desembolso, sin dudas, obligó al gobierno de Abascal a presionar a distintas zonas del Perú para la obtención de recursos. En ese sentido, por ejemplo, se sabe que el estanco del tabaco pagó en buena parte la defensa del reino a tal punto que dicho rubro colapso hacia 1816. Antes, los cultivadores y encargados del beneficio del tabaco en la zona de la rebelión habían entrado en conflicto con el Estado que prácticamente les había prohibido, bajo severas penas, que particulares se dediquen a ese negocio so pena de cárcel y expropiaciones (Anna 2003: cap. 1).

Entonces, por un lado, los malos funcionarios abusaban de los habitantes de Huánuco y alrededores. Por el otro, un Estado en crisis interfería de forma abusiva en la vida de dicha comunidad. En un universo más grande, el rey —el garante del orden social — se hallaba prisionero de los franceses. Por lo tanto, y en palabras de Barrington Moore (1989: 18), el límite tolerable, antes de que aparezca en boca de todos la palabra "injusticia", había sido superado con largueza hacía mucho. 


\section{El malestar de los huanuqueños según un testigo}

La Relación verídica y autentica de la Revolución [...] en la ciudad de Huánuco (Comisión Nacional del Sesquicentenario de la Independencia del Perú 1971: t. III, vol. 4: 195-227) fue escrita por el padre Pedro Ángel Yadó en septiembre de 1812, justamente cuando los implicados en el movimiento estaban siendo juzgados. En dicho escrito se ve con mayor claridad los motivos inmediatos que pudieron haber provocado el alzamiento.

El sacerdote habla casi de un imperio de la familia Llanos en Huánuco. De tal linaje, decía el sacerdote, salían los curas, subdelegados, miembros del cabildo, alcaldes, coroneles, tenientes y asesores. Por ejemplo, los antedichos subdelegados Diego García y Alfonso de Mejorada eran parientes de esta poderosa familia. El caso es que tal oligarquía se repartía entre ellos las mejores tierras al mismo tiempo que lucraban con los mejores negocios de la ciudad.

Así mismo, los Llanos y sus entenados, no tenían reparos en mandar a la cárcel a todo aquel que se atreviera a contradecirlos o a quien no pagara las deudas contraídas (en la generalidad de los casos de forma abusiva) con tan poderoso clan. El sacerdote no se cansa de repetir en su relato que toda esta gente era injusta y sin religión y que quienes principalmente eran víctimas de sus maldades eran los indios

60 panataguas, cuya condición era más que miserable. El odio que los huanuqueños sentían por este clan se azuzaba por el hecho de ser estos mandoncillos europeos: "Con estos gobernadores era imposible que los huanuqueños y panataguas no estuvieran disgustados, y como estos mandones son europeos, empezó hace tiempo a tirarse la ciudad contra los chapetones" (Yadó 1971 [1812]: t. III, vol. 4: 197). 
Como ocurrió principalmente entre el siglo XVII y XVIII, la contraposición entre chapetones (peninsulares) y americanos (criollos e indígenas) seguía más vigente que nunca ${ }^{5}$.

\section{Elementos de cultura política en la rebelión de Huánuco}

\section{La imagen del rey}

Como en buena parte de las rebeliones del siglo XVIII, la imagen del rey queda incólume en boca de los alzados:

[...] El rey es el dueño de la tierra y padre de la Patria de ahí que su poder sea patrimonial. De la misma manera (...) se veía al Monarca como "Delegado de Dios en la Tierra", de ahí que su majestad fuera inviolable. No obstante estos atributos, [se entendía a la par que] el monarca tenía un enorme deber que no era otro que el de buscar la felicidad de los súbditos, felicidad que sólo podía ser alcanzada con el ejercicio de la justicia (Torres Arancivia 2006: 108).

En las declaraciones y testimonios de implicados durante el proceso judicial aparecen dos tipos de referencias sobre la persona real. Las primeras alusiones tienen que ver con la imagen que los indios, criollos y mestizos tienen de su rey y las segundas, con lo que piensan ellos sobre la personalidad de Fernando VII, a la sazón, monarca cautivo de las fuerzas de invasión napoleónicas.

Desde un primer momento, todos los implicados e interrogados proclaman su lealtad al monarca español. Es así que hablan de fidelidad, amor al rey y de respetar al rey (Co-

5 Sobre ese conflicto véase el capítulo 4 de mi libro Corte de virreyes. El entorno del poder en el Perú del siglo XVII (Torres Arancivia 2014). 
misión Nacional del Sesquicentenario de la Independencia del Perú 1971: t. III, vol. 1: 69; t. III, vol. 2: 276). Hasta los personajes más comprometidos, como los líderes de la junta gubernativa conformada tras la invasión de Huánuco, proclamaron que "La insurrección no ha sido en nada contrarrestada, ni contra la monarquía, ni contra la patria, ni contra la religión" (Comisión Nacional del Sesquicentenario de la Independencia del Perú 1971: t. III, vol. 1: 279).

En ese sentido, las palabras Dios, rey y patria aparecen siempre asociadas tal cual se desprende de los siguientes ejemplos tomados del mismo tomo y volumen de la fuente anterior:

"Defender los derechos de nuestro amado soberano y de la Patria” (p. 77).

"Para el mejor servicio del rey y de la patria" (p. 103).

“Defensa de Dios, el rey y la nación” (p. 208).

"Religión, el rey y la patria" (p. 210).

Tal asociación es un fundamento sustentado en la filosofía medieval: la religión y la monarquía venían a ser, en esencia, anverso y reverso de una misma moneda. Por cientos de años el catolicismo había encontrado a un contundente defensor en el monarca español, por lo que la causa del rey era la misma que la de Dios. Es por ello que los religiosos de Huánuco no se cansaban en hacer referencia a las "dos majestades", la terrena y la divina; la de Dios y la del rey. Así, toda causa del monarca era una "causa sagrada" (Comisión Nacional del Sesquicentenario de la Independencia del Perú (1971: t. III, vol. 1, 212-213).

En ese sentido, la noción de patria no tiene la connotación que algún sector de la historiografía tradicional le ha querido dar al término asociándolo a un afán de libertad, de diferenciación con respecto a España, de separatismo, de idea del Perú como nación. Nada más alejado de la realidad. La patria 
se identifica como el patrimonio del rey que es la tierra de muchas generaciones de fieles súbditos que han tenido la enorme ventaja (así se entendía) de haber nacido en un reino cristiano bajo el recto gobierno de un príncipe también cristiano (Comisión Nacional del Sesquicentenario de la Independencia del Perú (1971: t. III, vol. 1: 401).

Por su parte, la imagen de Fernando VII es totalmente idealizada. Y con razón. El monarca aún no había tenido oportunidad de reinar y los criollos e indios tan solo conocían los sucesos de Bayona. Así lo dejó entrever el cura Ignacio de Villavicencio en un sermón que dio en Huánuco el 8 de diciembre de 1811, pocos meses antes de la rebelión: "Que el soberano Fernando es un vástago desgraciado de Borbón, que sufre la usurpación tirana del enemigo de la humanidad [Napoleón]. Consoladlo en las aflicciones de su cautiverio. Sostened la fe en su corazón" (Comisión Nacional del Sesquicentenario de la Independencia del Perú (1971: t. III, vol. 2: 718).

Ese mismo cura resultó ser, en la rebelión del año siguiente, uno de los cabecillas más importantes del movimiento. Capturado e interrogado, demostró qué bien informado estaba de los sucesos mundiales al mismo tiempo que declaraba que consideraba un terrible pecado la traición de lesa majestad: "Esos hombres [los de la Junta de Buenos Aires] han obrado mal contra los derechos de la Soberanía y contra toda ley, en erigir a sus autoridades desobedeciendo al Supremo Consejo de Regencia que está mandando a nombre de Fernando $7^{\circ}$ por su cautividad a quien públicamente ha jurado y protestado ser su vasallo y no serlo de otro alguno" (Comisión Nacional del Sesquicentenario de la Independencia del Perú (1971: T. III, vol. 2: 396).

Y no debe olvidarse que cuando los indios rebeldes regresaron a la ciudad de Huánuco tras la victoria en Ambo, muchos testigos afirman que lo hicieron vivando a Fernando VII y 
que luego comenzaron a dar dos vueltas a la plaza mientras uno de ellos enarbolaba un banderín sacado de la iglesia para luego jurar lealtad al rey y a la religión (Comisión Nacional del Sesquicentenario de la Independencia del Perú (1971: t. III, vol. 2: 275, 281).

Lo que puede colegirse de estos testimonios es que en 1812 aún prevalece una imagen del rey totalmente antiguorregimental: padre de la patria, garante de la justicia, propulsor del bien, etc. Se le añade a su figura el misticismo de la religión católica que la evangelización y el adoctrinamiento hacia los indígenas no se cansaron de subrayar. Al rey se le debía, pues, lealtad pero — a la par — se esperaba que él cumpliera con un pacto.

\section{La noción del pacto en la rebelión de 1812}

Es muy probable que durante las rebeliones del siglo XIX se haya reactivado la idea del pacto social que había funcionado durante el siglo XVII. Se entendía en aquel entonces que existía un pacto de tipo político que unía al monarca con sus súbditos y hasta la filosofía de la época lo había sustentado de forma no menos que elocuente. Uno de esos tratadistas que delineó la idea del pacto social fue Francisco Suárez (1548-1617). Según él, en tiempos inmemoriales, Dios entregó el poder y la soberanía a la comunidad de hombres y esta se lo dio al rey para que gobierne con justicia. Tal fundamento tenía hasta una lógica aristotélica: es más armonioso que el poder sea ejercido por un solo hombre que por varios. Lo primero es orden, lo segundo anarquía ${ }^{6}$.

6 Largo sería detenernos a analizar la obra De Legibus del gran Suárez. No obstante, se intenta una glosa. En la teoría de Suárez, Dios ha creado un orden natural que es bueno por esencia. De ese orden vienen leyes naturales que, como es obvio, propugnan el bien. Es de entenderse, entonces, 
Extrapoladas estas concepciones al Nuevo Mundo, pronto calaron entre los miembros de la elite criolla e indígena. Situación particular si se considera que ya en la península, a partir del siglo XVII, estas nociones comenzaban a ser criticadas y hasta vetadas por una monarquía pujante que no se cansaba de remarcar que su poder venía de Dios y no de la comunidad.

Los americanos entendían que el rey debía gobernar con justicia para dar tanto a criollos como a indios lo que merecían, entendiéndose —al mismo tiempo- de que si el rey no cumplía con su parte, su reinado podía devenir en tiranía, que es la corrupción del buen gobierno (Torres Arancivia 2014: II parte). François Guerra (1992) demostró hace ya algunos años cómo el pactismo de raíz escolástica cobró vigencia en el contexto de las revoluciones hispanoamericanas y, claro, el caso de Huánuco no fue una excepción.

Un pasquín que supuestamente fue realizado por un sacerdote implicado en la revuelta comenzaba de la siguiente ma-

que todo gobierno humano nace y se rige con esas leyes naturales que son preexistentes e imperecederas. Con esa lógica, se entiende, a su vez, que Dios no ha elegido entre todos los mortales a uno que, por su fuerza instintiva se ponga por encima de los demás como gobernante. Lo natural es que (en la argumentación del De Legibus) es el cuerpo social organizado quien recibe de Dios la autoridad y es esa sociedad quien se la da a un monarca para que gobierne con justicia y propugne el bien común. De esa manera se constituye un pacto entre el rey y los gobernados. De la misma manera, Suárez arremete contra el mal entendido absolutismo monárquico cuando sostiene que todo el pueblo se puede rebelar ante la autoridad si el monarca comienza a actuar como un tirano, que no es sino el hombre que recibió la soberanía divina (por intermedio del pueblo), pero que por perniciosa conducta se ha alejado de la búsqueda del bien común, de ahí que sea legítimo responder la fuerza con la fuerza. $\mathrm{Al}$ respecto, véase Gómez Robledo (1986: 143-144, 181). 
nera (Comisión Nacional del Sesquicentenario de la Independencia del Perú (1971: t. III, vol. 2: 339):

Nunca decirse se oyó

El rey a su trato faltase:

Porque nadie criticase;

Pero en fin ya sonó.

¿Y cómo el rey podía estar faltando al pacto social en esa coyuntura? Se entendía que permitiendo los vejámenes y abusos en los que se hallaban sumidos los criollos e indios de la región. Aunque ya desde mediados del siglo XVIII se hacía referencia a la disolución del pacto social por parte de la dinastía borbónica, tal vez el hecho de que esta vez el rey se hallara prisionero daba pie a que se postulara que sin rey el pacto carecía de garantía.

En todo caso, tanto en tiempos de Carlos IV como del prisionero Fernando VII, la idea de la unión de ribetes sagrados que unía al rey con sus súbditos indianos se estaba desmoronando en virtud del

[...] despotismo y comercio reprobados de los Subdelegados, contra quienes nada han podido las quejas anteriores de los pacientes. Poner en un solo pueblo, como en el de Panao cuatro o seis jueces; autorizar con providencias a los mismos repartidores de especies, para que se cobrasen de sus injustos precios, permitir que se les quitasen cuanto cosechaban, sin otra medida y otro precio que el que querían los propios tiranos; tolerar prisiones largas por estas clases de deudas, y aun sabiendo que eran insolventes los que las sufrían, decretar que en ellas entrasen los hijos e hijas por lo que debiesen padres, hermanos o maridos; últimamente, hacer repartos los mismos jueces y ejecutar en su favor estas propias extorsiones, injusticias y crueldades, era poner un continuo pábulo al fuego de la desesperación, y querer un milagro en que esta no descubriese su llama algu- 
na vez [Testimonio de Miguel Eyzaguirre, abogado de los insurrectos] Comisión Nacional del Sesquicentenario de la Independencia del Perú (1971: t. III, vol. 5: 77).

Sin lugar a dudas, predominaba la injusticia en la región y se llegó al punto en que ya no se podía aguantar más. En ese sentido, el cultivo de tabaco también fue motivo importante de conflicto, ya que los criollos y mestizos que se dedicaban a ese negocio en la zona vieron con estupor cómo el gobierno central ordenó que se estancara la producción de la hoja, lo que contradecía las disposiciones de libre comercio predominantes en el Virreinato desde 1778. Justamente el mismo sacerdote que escribió los sonetos del final del pacto se quejaba de cómo los subdelegados creaban ardides para hacerle creer a la gente que el tabaco cultivado por los particulares "daba moquillo y causaba la muerte" (Comisión Nacional del Sesquicentenario de la Independencia del Perú (1971: t. III, vol. 2: 400).

Sorprende, al mismo tiempo, cómo los huanuqueños intentaban reconstruir el antiguo pacto y no se cansaban de reavivar el pasado con el propósito de recrear una antigua forma de hacer política. Así, quien se adentre en el análisis de las fojas de los juicios de la rebelión descubrirá cómo aún se seguía citando a las Leyes de Indias, al jurisconsulto Solórzano y su Política indiana (1648), a las disposiciones del virrey Toledo (1569-1581), al letrado José de Acosta y los dictámenes de los concilios limenses $(1556,1561)$ (Comisión Nacional del Sesquicentenario de la Independencia del Perú (1971: t. III, vol. 3: 123 y ss.; t. IV: 73).

\section{Uso político de la imagen del inca}

A mediados de 1811, los pobladores de Huánuco decían que un misterioso personaje iba anunciando por esos lares la llegada del inca y que ese inca era el general rioplaten- 
se Juan José Castelli, que venía a instaurar un nuevo orden. Una tendera llamada Manuela Zavala decía, por ejemplo, que los indios se hallaban enojados, que no tenían libertad y que por eso iba a venir el hijo del inca y que Castelli tenía razón (Comisión Nacional del Sesquicentenario de la Independencia del Perú (1971: t. III, vol. 1: 124). Una anciana indígena llamada María Inés Ramos fue más precisa y señaló: "Que había venido un forastero descalzo con yanques, y que este había traído unas cartas en la que se decía que ya estaba próximo un descendiente de los Incas a cortarle el cuello a todos los españoles y devolverle la tierra a los indios (Comisión Nacional del Sesquicentenario de la Independencia del Perú (1971: t. III, vol. 1: 133).

Luego se supo que tal forastero era un indio llamado Antonio Rodríguez que decía haber estado en Cuzco y Potosí, donde se había enterado de la nueva del inca. Hasta decía que lo había conocido y que traía una carta y retrato de él, al mismo tiempo que le prometió que un nuevo tiempo iba a venir y que todos los españoles iban a morir (Comisión Nacional del Sesquicentenario de la Independencia del Perú (1971: t. III, vol. 1: 137). Por otro lado, rumores llegados de Tarma sostenían una noticia increíble: Fernando VII se hallaba preso en Jerusalén y que en esa santa ciudad había renunciado su corona a favor de un inca (Comisión Nacional del Sesquicentenario de la Independencia del Perú (1971: t. III, vol. 1: 174).

68 Es muy probable que todos estos rumores tuvieran un asidero en las informaciones que llegaban al virreinato provenientes de las campañas militares de Castelli en el Alto Perú, donde sus victorias militares le habían permitido formar un gobierno en Chuquisaca desde el cual propuso conferir el derecho al voto a los indígenas y librarlos de la servidumbre a la que estaban sometidos por las órdenes religiosas. En mayo de 1811, este caudillo celebró la libertad de los indígenas en las 
ruinas de Tiahuanaco al mismo tiempo que rindió un especial homenaje a los incas. No obstante, Castelli pronto sería derrotado por el gobernador del Cuzco Goyeneche en la batalla de Huaqui en junio de ese año (Sala i Vila 1996: 164).

Cuando en febrero del año siguiente estalló la rebelión de Huánuco, muchos dirigentes del movimiento, entre ellos Juan José Crespo y Castillo, siguieron avivando a su favor la idea del inca y el advenimiento de Castelli, solo que esta vez hasta manipularon el rumor de forma pintoresca: Crespo y Castillo se ufanaba de cartearse con Castelli, lo mismo que anunciaba de que ya no había rey y de que Goyeneche y Castelli se habían unido (Comisión Nacional del Sesquicentenario de la Independencia del Perú (1971: t. III, vol. 2: 13, $86,274,419)$.

¿Qué apreciaciones analíticas se pueden sacar de esta omnipresencia incaica en los prolegómenos de la rebelión y en el movimiento mismo? Varias cuestiones se pueden deducir. La primera es sostener que la imagen del inca en la zona de ceja de selva se seguía mostrando como difusa, tal como había ocurrido en tiempos de Juan Santos Atahualpa (1740-1750); la figura del inca no tenía, en lo absoluto, la misma carga simbólica que bien podía tener en el sur andino, a tal punto que los nativos del lugar no tuvieron ningún reparo en asumir que el argentino Castelli podía ser un inca. Segundo, la mención al posible arribo del inca bien podría ser interpretada como un intento extremo por reflotar el pacto con el monarca español: casi parecía un llamado de atención en el sentido de que si el rey no podía o no quería cumplir con las obligaciones que tenía para con sus súbditos indios, podía ser reemplazado por un gobernante que en los hechos (debió haber pesado muchos los sucesos de Tiahuanaco) sí estaba dispuesto a hacer justicia entre los nativos americanos. Finalmente, vale decir que algunos criollos (como Crespo y Castillo) intentaron utilizar la idea del inca- 
Castelli para ganar el apoyo de los nativos en una primera fase de la rebelión, pero que luego esta idea fue descartada cuando la endeble alianza entre ambos grupos sucumbió por los estallidos de violencia generados por la indiada.

\section{El plan político de la rebelión}

Tomando como base el análisis de los documentos que han sobrevivido de la rebelión de 1812 puede decirse que existía un plan político mínimo por parte de indígenas y criollos. Si se considera que el movimiento no era separatista ni independentista, se puede asumir que las propuestas políticas de los actores se movieran en el cauce del reformismo y hasta en el de la inmediatez, ya que los participantes buscaban anular, de una vez por todas, los abusos que estaban cometiendo los peninsulares españoles y el gobierno virreinal central.

De las declaraciones de los indígenas puede colegirse el siguiente plan (Comisión Nacional del Sesquicentenario de la Independencia del Perú (1971: t. III, vol. 1: 84, 111, 131, 137, 143, 174, 184, 282):

- Expulsar a los europeos peninsulares del reino.

- Lograr que el gobierno recaiga en americanos.

- Dar tierras a los indios.

- Reducir el tributo indígena.

- Lograr la unión entre mestizos e indígenas.

Por su parte, los criollos más bien se presentan ambiguamente en sus propuestas. Tal vez compartían con los indígenas el odio visceral o la simple animadversión hacia los chapetones, pero este sector más bien lo que buscaba eran reivindicaciones en cuanto a prelación se refiere. Sobre esto 
último, pedían acceso al gobierno regional, que se respeten las libertades económicas que se habían dado y que la administración virreinal no los ahogara más de lo que estaban.

No obstante, es difícil adentrarse en un plan político complejo. Este no podía darse por varias razones: la brevedad de la rebelión, su poco tiempo de preparación, la ausencia de líderes con arraigo y la lógica provinciana de la acción. Lo único que es recurrente es el odio hacia los peninsulares en esa zona, un odio que podía mover a la masa a la rebelión y aquí cabe la pregunta, ¿cuán irracional podía ser ese odio? La respuesta nos lleva por otro camino.

\section{6. "Viva el rey, muera el mal gobierno" o sobre la economía moral en la rebelión de Huánuco}

En 1971, el historiador inglés Edward Palmer Thompson (1924-1993) publicó un sesudo artículo en el que estudiaba los motines campesinos en la Inglaterra del siglo XVIII. En esas páginas, Thompson demostró que los motines de hambre no eran estallidos caóticos, sino que respondían a una lógica y disciplina moral. En otras palabras, lo que este historiador "descubrió" es que en una sociedad preindustrial, o en vías de serlo, los comportamientos económicos se definen a partir de valores morales o normas culturales que tienen como ejes los ideales de justicia y reciprocidad. A ese tipo de economía, Thompson la llamó "economía moral" (Thompson 1971). ${ }^{7}$

La economía moral como esquema de trabajo sirve para entender la lógica de las sociedades de antiguo régimen, al mismo tiempo que permite al investigador matizar nociones

7 La versión en castellano, con actualizaciones del autor, se encuentra en Thompson (1995). 
como explotación y motines irracionales. A la par, el esquema ayuda a erradicar el mito de la existencia de masas iletradas o analfabetas, desde la perspectiva política.

Esa interpretación permite ver el rol del pueblo como agente histórico. Según Thompson (1995: 216), los motines o revueltas no solo son movimientos desesperados que pretenden transformarse en revoluciones, sino que la violencia desatada también podría defender viejos derechos y costumbres tradicionales. Con esa mentalidad, un pueblo alzado intenta reflotar las ideas de bien público o las estrategias propias de un Estado patrimonial, porque su monarquía está pasando por un proceso de modernización que justamente busca acabar con esas formas tradicionales de hacer política o de entender la relación con los subordinados. En la Inglaterra que retrata Thompson, se trataba de un Estado que parecía moverse con la lógica de Adam Smith para erradicar la raigambre Tudor; en el Perú, podría ser el clímax de los afanes borbónicos por modernizar al pueblo que esos reyes ya veían como parte de una colonia frente a personas (en este caso, los huanuqueños) que seguían moviéndose con la lógica pactista que los Habsburgo habían dejado como imborrable impronta.

En el caso de los movimientos rebeldes americanos, muy pocas veces los investigadores se han propuesto aplicar el modelo de la economía moral. Tal vez el caso más conocido es el de Brooke Larson, quien en un buen artículo se aventuró a encontrar los límites de la propuesta de Thompson reformulada por James Scott y aplicada a los campesinos de Chayanta en el Alto Perú a fines del siglo XIX (Larson 1992). En el caso del Perú, lo han hecho Cecilia Méndez, a través de un artículo teórico más que de aplicabilidad (Méndez 1990), y Ward Stavig para el caso de la gran rebelión de 1780 (Stavig 1999). 
¿Cómo aplicar la economía moral para el caso de la rebelión de Huánuco de 1812? Hay que tener en cuenta que había un malestar generalizado ocasionado por la economía de la zona:

- El estado virreinal buscaba intervenir en la producción y comercio del tabaco.

- Se seguía cobrando el tributo a los indígenas a pesar de que este había sido abolido en marzo de 1811 por la regencia.

- Persistía un mecanismo parecido al reparto.

- Una elite de peninsulares españoles se había apoderado de las mejores tierras.

- Había monopolios.

- Había acaparamiento de cosechas.

Ante tal situación, los súbditos (tanto criollos como indígenas) no verán más alternativa que rebelarse, pero no para declarar la ruptura con respecto a su rey, sino para llamarle la atención sobre el desvió de su justicia. De cierta manera, la lógica del movimiento fue el reflote del pacto de tintes medievales-renacentistas que había unido a los súbditos peruanos con la monarquía desde el siglo XVI. La economía moral de los huanuqueños, panataguas y huamalíes se resumió en el atávico grito de "Viva el rey, muera el mal gobierno". El cabecilla más visible de la rebelión, Juan José Crespo y Castillo, lanzó tal grito luego de la victoria de Ambo: "Que cuando el confesante [Crespo y Castillo] lo nombraron de general dio dos vueltas por la plaza e hizo que los indios y toda la gente jurase a Fernando $7^{\circ}$ y a la religión diciendo muera el mal gobierno y viva Fernando $7^{\circ}$ (Comisión Nacional del Sesquicentenario de la Independencia del Perú (1971: t. III, vol. 2, 100). 
Tal grito es recurrente en la historia del Perú. Tal vez el primero de ellos se dio mientras se llevaba a cabo el asesinato de Pizarro a manos de los almagristas. Luego, esa misma invocación aparecería en la rebelión de Gonzalo Pizarro y con mayor fuerza, ya en el siglo XVIII, tanto en los grandes movimientos como los de Juan Santos y Túpac Amaru, como en los más pequeños (por ejemplo, en la llamada rebelión de los pasquines, en Arequipa, 1780).

En todo caso, ese grito busca legitimar la rebelión (Lohmann Villena 1977: 17) y los rebeldes de Huánuco encontraron tal legitimación en la tradición escolástica de Antiguo régimen que sostenía que casi era un deber moral corregir el mal gobierno. Como había ocurrido en el Perú del siglo XVI, los alzados de Huánuco, Panataguas y Huamalíes entendieron que: "El poder del común de cualquier república, villa o aldea es superior al del mismo monarca" (Lohmann Villena1977: 43).

La idea del pacto social, el intento de corregir el mal gobierno, la propuesta de alternativas ante el vacío del poder, los intentos de reconstruir los puentes de negociación con la monarquía presentaban el Viva el Rey. El abuso de los chapetones, el absolutismo de Abascal, la pobreza del reino, la marginación de los criollos y la explotación inmisericorde de los indígenas de la región constituían el mal gobierno.

La rebelión de Huánuco fue una expresión clara de economía moral, pero los tiempos estaban cambiando vertiginosamente,

74 tan rápido que en menos de una década ya no habría monarca con quien pactar, pues los peruanos descubrirían, muy a su pesar, que Fernando VII "El deseado", como cabeza de la España imperial, ya no tenía la connotación mística del Antiguo régimen, sino que era el más común de todos los mortales.

Recibido: 09 de noviembre del 2015

Aceptado: 10 de diciembre del 2015 


\section{Bibliografía}

ABASCAL, Fernando de

1944 [1816] Memoria de Gobierno. 2 volúmenes. Sevilla: Editorial Católica.

ANNA, Thimothy

2003 La caída del gobierno español en el Perú. El dilema de la independencia. Lima: Instituto de Estudios Peruanos.

BONILLA, Heraclio

1981 "Clases populares y Estado en el contexto de la crisis colonial". En Bonilla, Heraclio (editor). La Independencia en el Perú. Segunda edición. Lima: Instituto de Estudios Peruanos.

CHASSIN, Joelle

1989 Bataille juridique et affrontement des mentalites a la veille de l'independance peruvienne : le soulevement de Huanuco et sa repression judiciaire. París: Ersipal.

EGUIGUREN, Luis Antonio

1912 Guerra separatista, 1812. Lima: San Martí.

GÓMEZ, Ignacio

1886 El origen del poder político según Francisco Suárez. San José: Universidad Autónoma de Centro América.

GUERRA, François

1992

Modernidad e independencias: ensayos sobre las revoluciones hispánicas. Madrid: MAPFRE.

LARSON, Brooke

1992 "Explotación y economía moral en los Andes del sur: hacia una reconsideración crítica". Historia Crítica. Bogotá, número 6, pp. 75-97. 
LOHMANN VILLENA, Guillermo

1977 Las ideas jurídico-politicas en la rebelión de Gonzalo Pizarro: la tramoya doctrinal del levantamiento contra las leyes nuevas en el Perú. Valladolid: Casa Museo Colón.

MÉNDEZ, Cecilia

1990 “Economía moral versus determinismo económico?: dos aproximaciones a la historia colonial hispanoamericana". Historia y Cultura. Lima, número 20, pp. 361-366.

MOORE, Barrington

1989 La injusticia: bases sociales de la obediencia y la rebelión. México D.F.: UNAM.

O’PHELAN, Scarlett

1985 Un siglo de rebeliones anticoloniales. Perú y Bolivia 17001783. Cuzco: Centro Bartolomé de las Casas.

PUENTE, José Agustín de la

"La Independencia". En Historia general del Perú. Lima: Brasa, tomo VI.

SALA I VILA, Nuria

$1996 \quad Y$ se armó el tole tole: tributo indígena y movimientos sociales en el Virreinato del Perú, 1790-1814. Huamanga: Instituto de Estudios Regionales "José María Arguedas".

STAVIG, Ward

The world of Túpac Amaru. Conflict, community, and identity in colonial Peru. Nebraska: University of Nebraska Press.

TEMPLE, Ella Dunbar

1971

Conspiraciones y rebeliones del siglo XIX: La revolución de Huánuco, Panatahuas y Huamalíes. Estudio preliminar de Ella Dunbar Temple. En COMISIÓN NACIONAL DEL SESQUICENTENARIO DE LA INDEPENDENCIA DEL PERÚ. 
Colección Documental de la Independencia del Perú. Tomo III, volumen 2, $97 \mathrm{p}$.

THOMPSON, E. P.

1971 "The moral economy of the English crowd in the eigteenth century". Past and Present. Oxford, número 50, pp. $76-136$.

1995 Costumbres en común. Barcelona: Crítica.

TORRES ARANCIVIA, Eduardo

2006 "La imagen del rey en un siglo de rebeliones. Poder, buen gobierno, tiranía y legitimidad en el Perú Borbónico". Diálogos en Historia. Lima, número 4, pp. 107-134.

2014 El concepto de violencia en los Andes. Significado y discurso, siglos XVI y XVII. Tesis para optar al grado de doctor en Estudios Andinos. Lima: Pontificia Universidad Católica del Perú.

2014 Corte de virreyes. El entorno del poder en el Perú del siglo XVII. Segunda edición. Lima: Pontificia Universidad Católica del Perú, Instituto Riva Agüero del Perú.

VARALLANOS, José

1959 Historia de Huánuco: introducción para el estudio de la vida social de una región del Perú, desde la era prehistórica a nuestros días. Buenos Aires: López.

VARGAS UGARTE, Rubén

1966 Historia general del Perú. Tomo V. Lima: Milla Batres.

YADÓ, Pedro Ángel

1971 [1812] "Relación verídica y autentica de la Revolución [...] en la ciudad de Huánuco". En COMISIÓN NACIONAL DEL SESQUICENTENARIO DE LA INDEPENDENCIA DEL PERÚ. Colección Documental de la Independencia. Lima, tomo III, volumen 4, pp. 195-227. 
Cultura política y economía moral en la rebelión de Huánuco, Panataguas y Huamalíes (1812) 